\title{
Pellets plásticos na praia de Santa Cruz dos Navegantes, Guarujá (SP), durante evento de frente fria no inverno de 2019
}

\author{
Victor Vasques Ribeirol; Vitória Rocha Dos Santos ${ }^{l}$
}

\victorvasquesribeiro@outlook.com

1. Centro Universitário São Judas - Campus Unimonte - Santos, SP - Brasil.

Histórico do Artigo:

Recebido em: 16 de dezembro de 2019 Aceito em: 28 de abril de $2020 \quad$ Publicado em: 30 de abril de 2020

Resumo: A praia de Santa Cruz dos Navegantes está localizada no município do Guarujá, na porção central do litoral do estado de São Paulo. Próximo a esta praia está o Canal do Porto de Santos, configurado como uma fonte emissora de pellets plásticos para os ambientes marinhos. Em praias arenosas próximas a fontes emissoras, principalmente no inverno e após eventos de entrada de frente fria, as quantidades de pellets são elevadas. Este estudo teve o objetivo de determinar a influência de um evento de entrada de frente fria do inverno de 2019 na quantidade de pellets encontrados na praia de Santa Cruz dos Navegantes, além de supor a proximidade das fontes emissoras. Durante seis campanhas de coletas consecutivas, sendo três anteriores e três posteriores ao pico de entrada de frente fria, 30,0 $\mathrm{m}^{2}$ de sedimentos superficiais foram amostrados a cada campanha. Essa praia foi considerada ideal para este tipo de pesquisa, pois a quantidade de pellets foi de Baixa $(0,679)$ a Muito Alta $(5,105)$ após o pico da entrada de frente fria, com fontes emissoras consideradas próximas e baixa incidência de fatores que podem soterrar os pellets nos sedimentos e subestimar os valores obtidos. A continuidade da aplicação dos métodos presentes neste estudo é imprescindível para o monitoramento e avaliação dos pellets em praias arenosas, principalmente naqueles locais próximos a fontes emissoras destes grânulos.

Palavras-chave: Pellets, Microplásticos, Praia Arenosa, Guarujá.

\section{Plastic pellets on santa cruz dos navegantes beach, guarujá (sp), during a cold front event in the winter of 2019}

\begin{abstract}
The Santa Cruz dos Navegantes beach is located in the city of Guaruja, in the central portion of the coast of the state of São Paulo. Next to this beach is the Channel of the Port of Santos, configured as a source of plastic pellets for marine environments. On sandy beaches near the sources, especially during the winter and after cold front entrance events, the amounts of pellets are high. This study aimed to determine the influence of a cold front entry event of the winter of 2019 on the amount of pellets found on Santa Cruz dos Navegantes beach, besides assuming the proximity of the sources. During six consecutive collection campaigns, three of which were previous and three after the cold front entry peak, $30,0 \mathrm{~m}^{2}$ of surface sediments were sampled each campaign. This beach was considered ideal for this type of research, because the amount of pellets was from Low $(0,679)$ to Very High $(5,105)$ after the peak of cold front entry, with nearby sources and low incidence of factors that can bury the pellets in the sediments and underestimate the values obtained. The continuity of the application of the methods present in this study is essential for the monitoring and evaluation of pellets on sandy beaches, especially in those places near sources of these granules.
\end{abstract}

Keywords: Pellets, Microplastics, Sandy Beach, Guarujá. 


\section{Pellets de plástico en la playa de santa cruz dos navegantes, guarujá (sp), durante el evento de frente frío al invierno 2019}

Resumen: La playa de Santa Cruz dos Navegantes se encuentra en la ciudad de Guaruja, en la parte central de la costa del estado de Sao Paulo. Junto a esta playa se encuentra el Canal del Puerto de Santos, configurado como fuente de pellets de plástico para ambientes marinos. En las playas de arena cerca de las fuentes, especialmente durante el invierno y después de eventos fríos de entrada frontal, las cantidades de pellets son altas. Este estudio tenía como objetivo determinar la influencia de un evento de entrada frente al frío del invierno de 2019 en la cantidad de pellets encontrados en la playa de Santa Cruz dos Navegantes, además de asumir la proximidad de las fuentes. Durante seis campañas consecutivas de recolección, tres de las cuales fueron anteriores y tres después del pico de entrada frontal frío, se muestrearon $30,0 \mathrm{~m}^{2}$ de sedimentos superficiales en cada campaña. Esta playa fue considerada ideal para este tipo de investigación, ya que la cantidad de pellets era de Baja $(0,679)$ a Muy Alta $(5,105)$ después del pico de entrada frente fria, , con fuentes de emisión consideradas cercanas e de baja incidencia de factores que pueden enterrar pellets en sedimentos y subestimar los valores obtenidos. La continuidad de la aplicación de los métodos presentes en este estudio es esencial para el seguimiento y evaluación de pellets en playas de arena, especialmente en aquellos lugares cercanos a fuentes de estos grânulos.

Palabras clave: Pellets, Microplásticos, Playa de Arena, Guarujá.

\section{INTRODUÇ̃̃o}

As praias arenosas são ambientes naturais que sofrem com a contaminação por diversos resíduos de origem antropogênica, principalmente o plástico (ALLSOPP et al., 2005; ABDILI et al., 2018).

Os pellets plásticos (Figura 1) são grânulos utilizados como matéria-prima na produção de plásticos (CUNHA, 2017), que podem ser perdidos aos ambientes marinhos em locais que os produzem, transportam, armazenam e distribuem (PEREIRA, 2011; PEREIRA et al., 2014; FALCÃ0, 2015; RYAN et al., 2018).

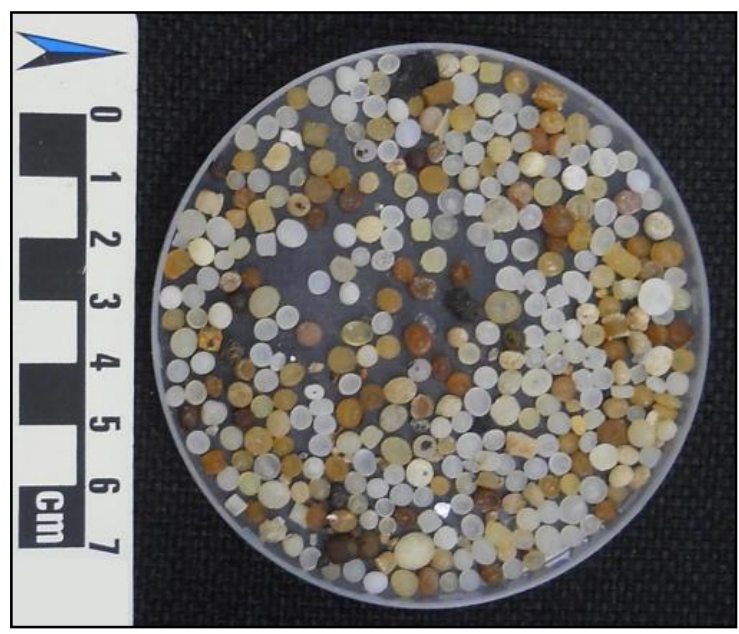

Figura 1. Pellets plásticos coletados em praias do estado de São Paulo, Brasil Fonte: FALCÃ0; SOUZA, 2011. 
As maiores quantidades de pellets são encontradas em praias arenosas próximas a estes locais que os perdem. Durante o inverno e após eventos de entrada de frente fria, devido à hidrodinâmica dos ambientes marinhos, são encontrados ainda mais pellets nessas praias (EPA, 1992; MANZANO, 2009; TURRA et al., 2014; GOUVÊA, 2015; MOREIRA et al., 2016a; ALVES et al., 2018).

Os pellets são facilmente visualizados e coletados durante maré baixa, ocasião que expõe a linha de deixa da maré alta antecessora. 0 trânsito de veículos, a limpeza da praia e a movimentação de banhistas podem soterrar os pellets nos sedimentos, subestimando os valores obtidos (TURRA et al., 2014; MOREIRA et al., 2016b; HIRATA, 2017; FANINI, 2018).

Devido ao seu peso, densidade e composição, esses grânulos são amplamente transportados nos oceanos, sendo degradados morfologicamente e quimicamente (BOURNE, 1982; IVAR D0 SUL et al., 2009; FALCÃ0; SOUZA, 2011; ANDRADY, 2011; FERNANDIN0 et al., 2015; MOREIRA et al., 2016a; MOREIRA et al., 2016b; VEERASINGAM et al., 2016a; HIRATA, 2017; FANINI, 2018).

Quanto maior o tempo de permanência destes grânulos nos oceanos, maior sua degradação, causada pela ação da luz solar e o intemperismo. Resulta-se em pellets de colorações amareladas e escuras e sem formato identificável (ANDRADY, 2000; KARAPANAGIOTI \& KLONTZA, 2007; KARAPANAGIOTI \& KLONTZA, 2008; FOTOPOULOU \& KARAPANAGIOTI, 2012; VEERASINGAM et al., 2016b; LOUR0 \& WIDMER, 2017; KARLSSON et al., 2018).

0s pellets podem atuar como vetor para diversos poluentes orgânicos persistentes (POPs) e metais (MAT0 et al., 2001; TAKADA, 2006; 0GATA et al., 2009; HESKETT et al., 2012; HARATSARIS, 2018; GORMAN et al., 2019), afetando a biodiversidade, a economia e o turismo (BLIGHT \& BURGER, 1997; BROWNE et al., 2008; COLABU0N0 et al., 2010; ALMEIDA, 2011; END0 et al., 2013; ANDRADE, 2014; NOBRE et al., 2015; MIRANDA \& CARVALHO-SOUZA, 2016).

No Brasil, existem diversas fontes emissoras de pellets para os ambientes aquáticos, presentes num conjugado logístico junto à costa, com a atuação de mais de 30 portos e diversas indústrias petroquímicas e empresas logísticas. Destes 30 portos, 14 importam e exportam pellets, com destaque para o porto de Santos (PEREIRA, 2011; PEREIRA et al., 2014).

0 presente estudo teve como objetivo determinar se um evento de entrada de frente fria pode influenciar a quantidade de pellets plásticos na praia de Santa Cruz dos Navegantes. Além disso, buscou-se supor a proximidade das fontes emissoras destes pellets. 
Pellets plásticos na praia de Santa Cruz dos Navegantes, Guarujá (SP), durante evento de frente fria no inverno de 2019

\section{MATERIAL E MÉTODOS}

Santa Cruz dos Navegantes, no município do Guarujá, na porção central do litoral do estado de São Paulo (GUIMARÃES, 2008; SILVA, 2011; FERREIRA \& LOPES, 2013), está situada próxima ao Porto de Santos (Figura 2), o maior da América Latina. Diversas indústrias e empresas na região podem atuar como fontes emissoras de pellets (PEREIRA, 2011; PEREIRA et al., 2014).

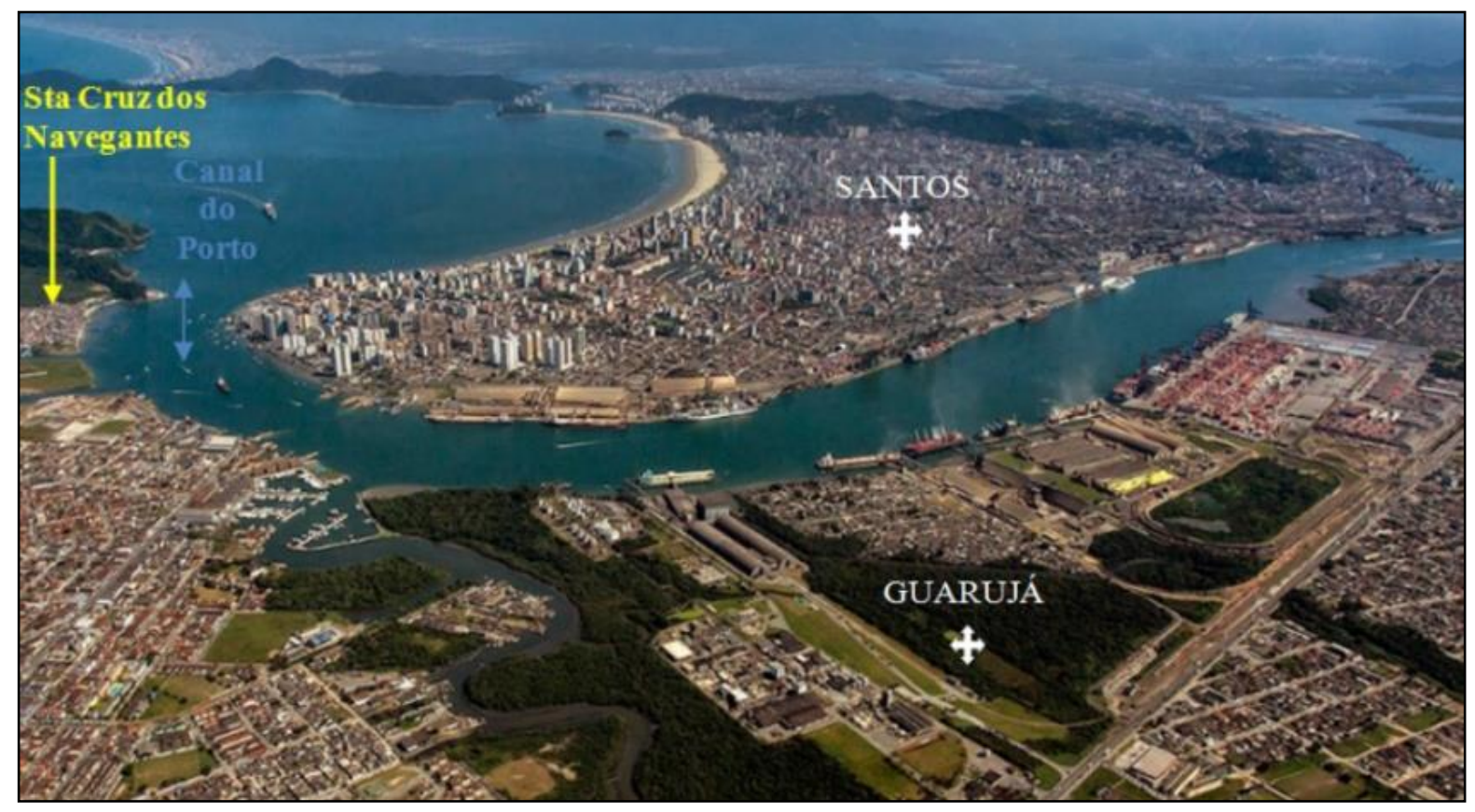

Figura 2. Santa Cruz dos Navegantes e Canal do Porto de Santos e Guarujá. Fonte: DALMO DUQUE DOS SANTOS, 2014 aриd RIBEIRO, 2019.

Foram realizados os seguintes procedimentos metodológicos: i) consulta para determinação do pico de entrada de frente fria, ii) trabalhos de campo e verificação de fatores que podem soterrar os pellets, iii) Índice de Poluição por Pellets (IPP), iv) análise de tendência e v) classificação morfológica.

i) Pico de entrada de frente fria

Para selecionar o período de coleta, objetivando três campanhas anteriores e três campanhas posteriores ao evento de pico de entrada de frente fria, o mesmo foi consultado no Núcleo de Pesquisas Hidrodinâmicas (NPH) da Universidade Santa Cecília (Unisanta). 
ii) Trabalhos de campo e Fatores que soterram os pellets

Durante maré baixa (MARINHA D0 BRASIL, 2019), as campanhas de coleta foram direcionadas para o sedimento superficial da linha de deixa de maré (MANZAN0, 2009; G0UVÊA, 2015; HIRATA, 2017; ALVES et al., 2018; RIBEIR0, 2019), local onde os resíduos foram recentemente depositados.

Foram amostrados $30,0 \mathrm{~m}^{2}$ a cada campanha. Para que fosse possível selecionar os 30,0 $\mathrm{m}^{2}$ na sinuosa linha de deixa de maré, 30 quadrantes de $1,0 \mathrm{~m}^{2}$ foram amostrados, acompanhando tal linha (Figura 3). Manualmente, os pellets visíveis foram coletados, devidamente armazenados e etiquetados.

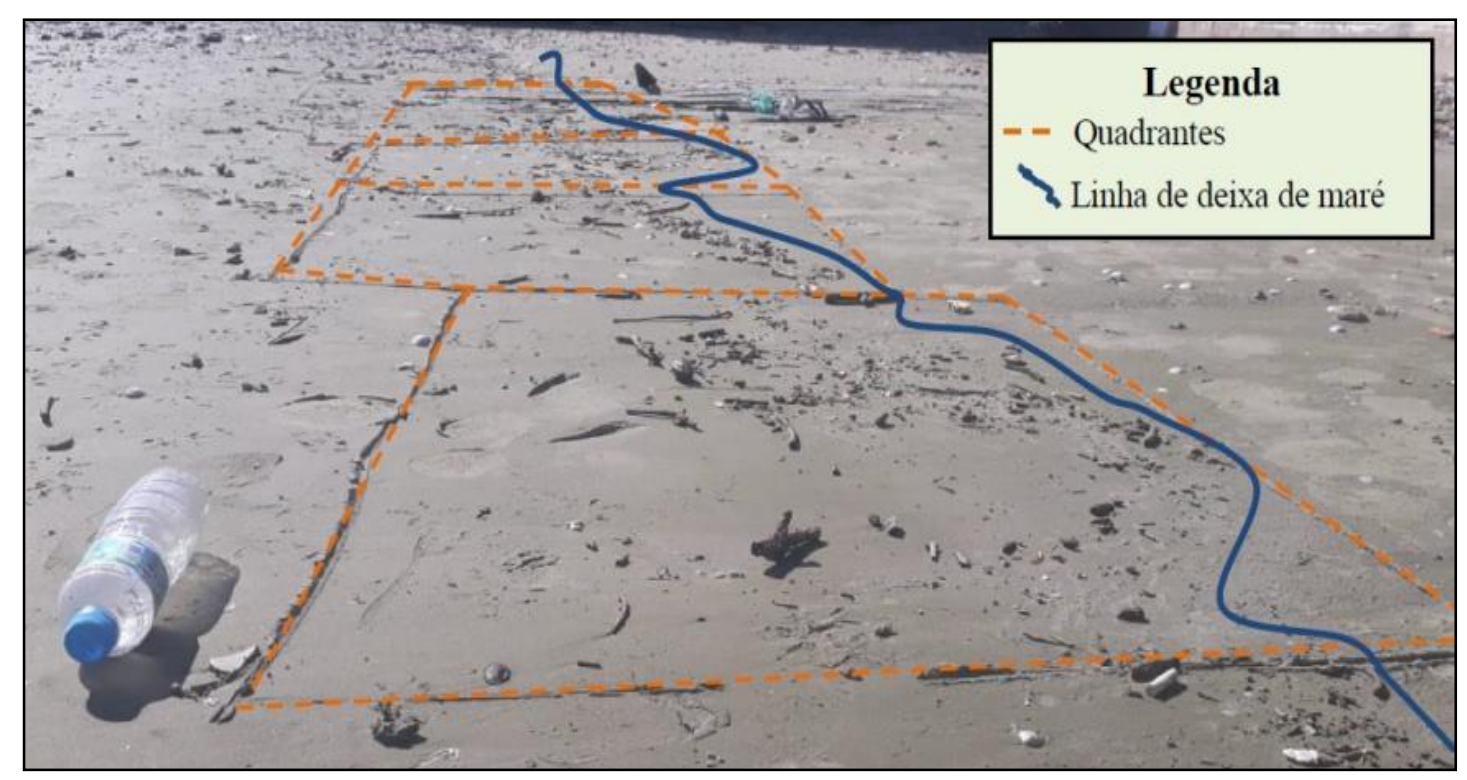

Figura 3. Quatro quadrantes a serem amostrados

Fonte: Arquivo Pessoal, 2019.

Durante as campanhas, caso fossem avistados veículos ou a realização da limpeza da praia, os colaboradores seriam abordados, de forma amigável e dialógica (BOHM, 2005; MÓNICO et al., 2017), para responderem qual a periodicidade em que transitam pelo sedimento ou o limpam. Além disso, buscou-se em campo, observar a movimentação de banhistas em comparação com praias movimentadas, como as de Santos (SP), próximas ao local estudado.

iii) Índice de poluição por Pellets (IPP)

A caracterização física da poluição por pellets na praia de Santa Cruz dos Navegantes foi calculada através do IPP (FERNANDIND0 et al., 2015; ALMEIDA, 2018): 
Pellets plásticos na praia de Santa Cruz dos Navegantes, Guarujá (SP), durante evento de frente fria no inverno de 2019

$$
I P P=\left[a(\text { pellets }) / v\left(m^{2}\right)\right] \cdot p
$$

onde $a$ é abundância de pellets coletados, $v$ é $o$ volume de sedimento analisado, em $\mathrm{m}^{2}$, e $p$ é 0 coeficiente de correção do IPP $(p=0,02)$. Portanto, variando de 0,0 a maior de 3,0, o IPP é classificado de Muito Baixo a Muito Alto (Tabela 1).

Tabela 1. Classificação do Índice de Poluição por Pellets (IPP)

\begin{tabular}{cc}
\hline IPP & Classificação \\
\hline $0,0<\operatorname{IPP}<0,5$ & Muito Baixo \\
$0,5<\operatorname{IPP}<1,0$ & Baixo \\
$1,0<\operatorname{IPP}<2,0$ & Moderado \\
$2,0<\operatorname{IPP}<3,0$ & Alto \\
IPP $>3,0$ & Muito Alto \\
\hline
\end{tabular}

Fonte: Adaptado de FERNANDIN0 et al., 2015 e ALMEIDA, 2018

iv) Análise de Tendência

A Análise de Tendência foi aplicada utilizando o Modelo de Tendência Quadrático do suplemento Action Stact do software Excel, que considerou as densidades médias (pellets $/ \mathrm{m}^{2}$ ) encontradas a cada coleta. Este método estatístico foi escolhido devido a sua capacidade de demonstrar variações físicas na linha de costa (QUEIR0Z et al., 2016), sendo aplicado no presente artigo, de forma apenas gráfica, para determinar a sinergia entre a quantidade de pellets e a entrada de frente fria.

v) Classificação Morfológica

0 tempo de permanência dos pellets em ambientes marinhos foi determinado a partir da adaptação dos estudos de Manzano (2009), Gouvêa (2015), Hirata (2017), Alves et al. (2018) e Ribeiro (2019). 
Foram analisados 1.200 pellets, sendo 200 de cada campanha de coleta, escolhidos ao acaso, utilizando três categorias de separação: Recentemente produzidos (de cores semitransparentes e brancas, com exceção dos sem formato identificável), Desgastados (de cores cobre claro e escuro, somados àqueles sem formato identificável de todas as cores) e Indefinidos (coloridos e pretos, com formato identificável).

Para classificar as formas dos pellets encontrados, oito formatos pré-determinados foram buscados entre as amostras, sendo estes: a) retangular, b) cúbico, c) cilíndrico grosso, d) cilíndrico fino, e) cilíndrico achatado, f) esférico achatado, g) ovoide e, por último, h) disforme, que não se enquadra em nenhuma das anteriores (HIRATA, 2017).

\section{RESULTADOS E DISCUSSÃ0}

i) Pico de entrada de frente fria

Na região, durante o período de inverno ocorre um aumento da frequência, intensidade e velocidade de deslocamento de frentes frias. As maiores alturas de onda são encontradas nesse período, alcançando entre 2,0 e 3,0 metros (STEIN, 2018).

0 pico da frente fria selecionado no presente estudo foi o mais intenso do inverno de 2019, que ocasionou ventos intensos, mar agitado, ondulações elevadas, de 2,9 metros e nível do mar acima da tábua de marés prevista na Baía de Santos em 03/08/19, às 4h (NPH, 2019a; NPH, 2019b). Portanto, o período selecionado para as campanhas de coleta de pellets se deu entre 31 de julho e 05 de agosto de 2019, compreendendo três campanhas de coletas anteriores e três posteriores ao evento de pico.

ii) Trabalhos de campo e Fatores que soterram os pellets

Durante o período de coleta, foram avistados quatro veículos transitando pelo sedimento. Todos os motoristas abordados afirmaram que passam brevemente pelo sedimento. 0s dois motoristas que atuam como vendedores de companhias de gás (Figura 4A e 4B) afirmaram que transitam pelo sedimento em aproximadamente duas vezes por semana.

0 vendedor autônomo de frutas (Figura 4C) afirmou que transita pelo sedimento uma vez por semana, aos domingos. 0 colaborador que realiza a limpeza da praia de forma manual e 
Pellets plásticos na praia de Santa Cruz dos Navegantes, Guarujá (SP), durante evento de frente fria no inverno de 2019

com rastelo e carrinho de mão e sacos de lixo (Figura 4E) afirmou que a faz todos os dias pela manhã, e destacou ainda que o caminhão de coleta de resíduos (Figura 4D), no recolhimento de sacos de lixo, entra em apenas uma parte do sedimento, não chegando a linha de deixa de maré.

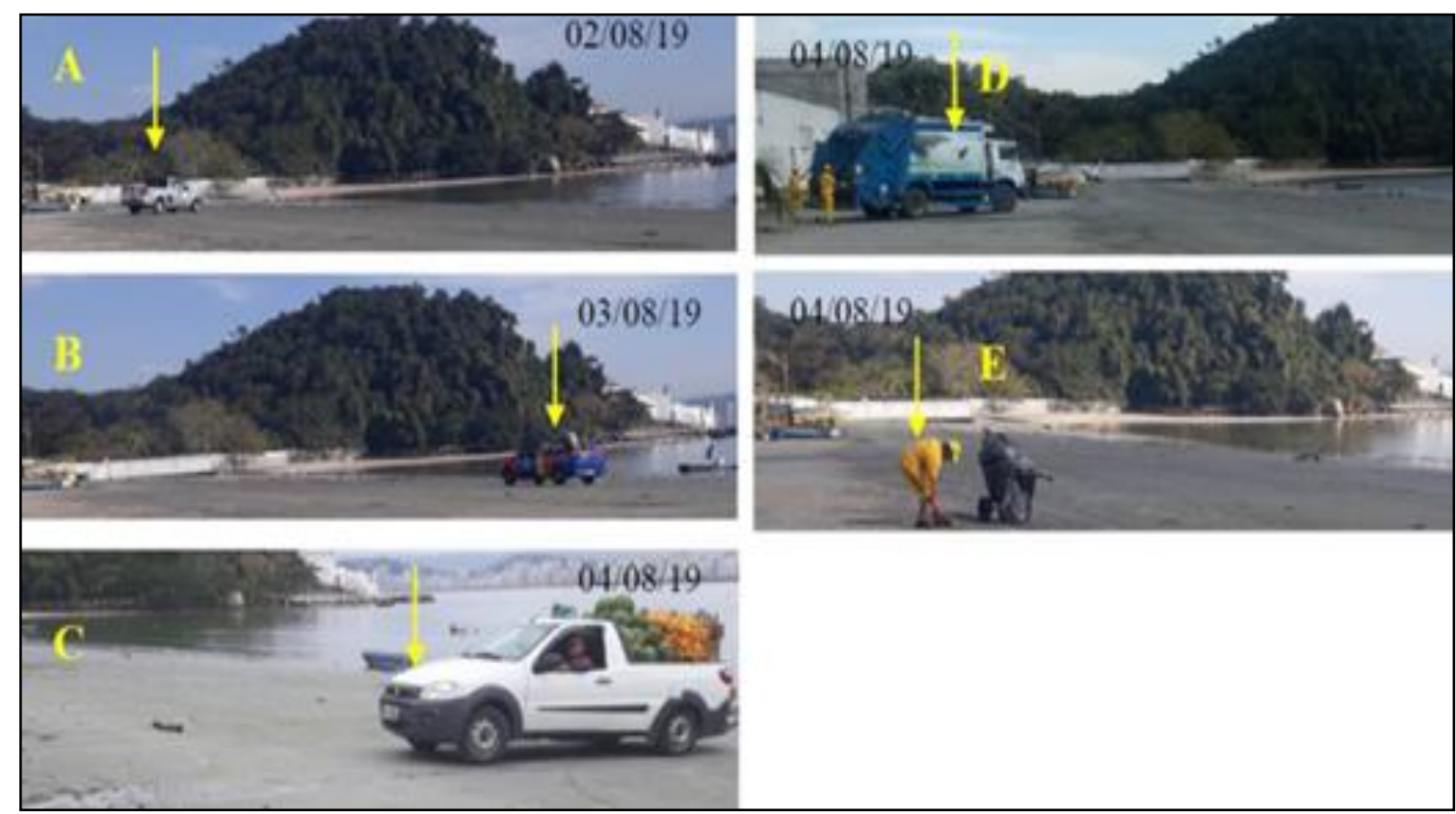

Figura 4. Fatores que podem soterrar os pellets Fonte: Arquivo Pessoal, 2019.

A movimentação de banhistas, caracterizada de forma visual, foi baixa na praia de Santa Cruz dos Navegantes. Em praias próximas, como as de Santos, além da massiva movimentação de banhistas (MANZAN0, 2009), a limpeza da praia é diária e faz uso de caminhões e tratores que transitam por diversas ocasiões em grande parte do sedimento, inclusive na zona de deixa de maré. Portanto, a praia de Santa Cruz dos Navegantes pode ser considerada ideal na região para valores mais precisos quanto à quantificação de pellets plásticos.

\section{iii) Índice de Poluição por Pellets}

Nos $180 \mathrm{~m}^{2}$ de sedimento analisados, ao longo de seis campanhas de coleta, foram encontrados 19.833 pellets. Na campanha inicial, em 31 de julho, foi encontrada a menor quantidade de pellets $\left(33,93\right.$ pellets $\left./ \mathrm{m}^{2}\right)$ e, consequentemente, menor IPP $(0,679)$, considerado Baixo. Na campanha de coleta após o evento de pico de entrada de frente fria foi encontrada a maior quantidade de pellets $\left(255,23\right.$ pellets $\left./ \mathrm{m}^{2}\right)$, e consequentemente, maior IPP $(5,105)$, considerado Muito Alto. Então, tal quantidade entrou em declínio, até a média de 114,03 
pellets/ $\mathrm{m}^{2}$ na última campanha de coleta, em 05 de agosto de 2019, porém, ainda com IPP classificado como Alto (Tabela 2).

Tabela 2. Densidade de pellets, IPP e classificação a cada campanha de coleta

\begin{tabular}{cccccccc}
\hline $\begin{array}{c}\text { Data } \\
(2019)\end{array}$ & $\begin{array}{c}\text { Pellets/m } \\
\mathbf{2} \\
\text { (Média da } \\
\text { campanha) }\end{array}$ & IPP & Classe & Período & $\begin{array}{c}\text { Pellets/m } \\
\mathbf{2} \\
\text { (Média do } \\
\text { período) }\end{array}$ & $\begin{array}{c}\text { IPP } \\
\text { (Média do } \\
\text { periodo) }\end{array}$ & Classe \\
\hline 31.07 & 33,93 & 0,679 & Baixo & Antes do \\
01.08 & 51,77 & 1,035 & Moderado & $\begin{array}{c}\text { pico de } \\
\text { frente fria }\end{array}$ & 49,77 & 0,995 & Baixo \\
02.08 & 63,63 & 1,273 & Moderado & Muito Alto & Após o pico \\
de frente \\
03.08 & 255,23 & 5,105 & 170,59 & 3,412 & Muito \\
04.08 & 142,50 & 2,850 & Alto & fria & & & \\
05.08 & 114,03 & 2,281 & Alto & Alto & & & \\
\hline
\end{tabular}

Fonte: Arquivo Pessoal, 2019.

Ao considerar o período anterior ao evento de pico de entrada de frente fria, ou seja, as três campanhas de coleta anteriores, a média de pellets $\left(49,77\right.$ pellets $\left./ \mathrm{m}^{2}\right)$ teve IPP classificado como Baixo $(0,995)$. No período após tal evento, ou seja, as três campanhas de coleta posteriores, a média de pellets $\left(170,59\right.$ pellets $\left./ \mathrm{m}^{2}\right)$ teve IPP classificado como Muito Alto (3,412). Portanto, este é o primeiro indicativo observado que tal evento pode influenciar na quantidade de pellets encontrados na praia de Santa Cruz dos Navegantes, aumentando-a significativamente.

iv) Análise de Tendência

A Análise de Tendência de Modelo de Tendência Quadrático foi apresentada no Gráfico 1, revelando o que foi explanado no cálculo do IPP: que a quantidade média de pellets aumenta significativamente em conformidade com a chegada do pico de entrada de frente fria, e logo após, entra em declínio (Gráfico 1). Portanto, foi confirmado estatisticamente que tal evento foi capaz de aumentar significativamente a quantidade de pellets depositados na praia de Santa Cruz dos Navegantes. 
Pellets plásticos na praia de Santa Cruz dos Navegantes, Guarujá (SP), durante evento de frente fria no inverno de 2019

Gráfico 1. Análise de Tendência de Modelo Quadrático das médias de pellets

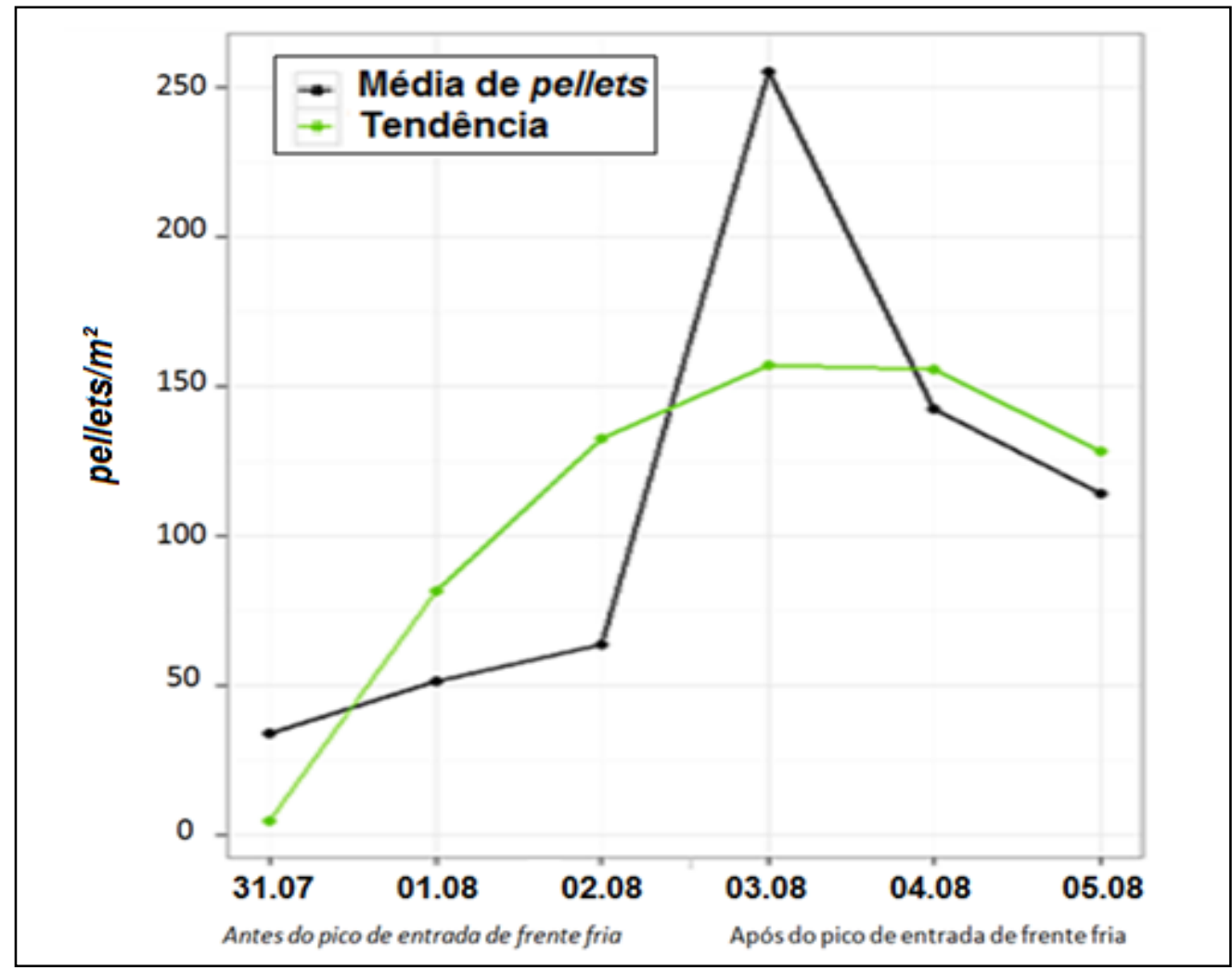

Fonte: Arquivo Pessoal, 2019.

A utilização deste método estatístico foi satisfatória, pois atendeu o objetivo de determinar a tendência da média de pellets durante um evento de pico de entrada de frente fria. Entretanto, em um estudo com mais campanhas de coleta, durante outras estações e eventos de entrada de frente fria, este método poderia ser ainda mais preciso. Ainda assim, este método pode subsidiar replicações em estudos futuros realizados nesta e em outras praias.

\section{v) Classificação Morfológica}

Foram analisados 1.200 pellets morfologicamente, sendo, 200 grânulos escolhidos aleatoriamente de cada uma das campanhas de coleta. Foram encontradas oito cores e formatos distintos, sendo estes: semitransparente; branco; cobre claro; cobre escuro; preto; cinza; azul; verde; e retangular; cúbico; cilíndrico grosso; cilíndrico fino; cilíndrico achatado; esférico achatado; ovoide; e disforme (Figura 5). 


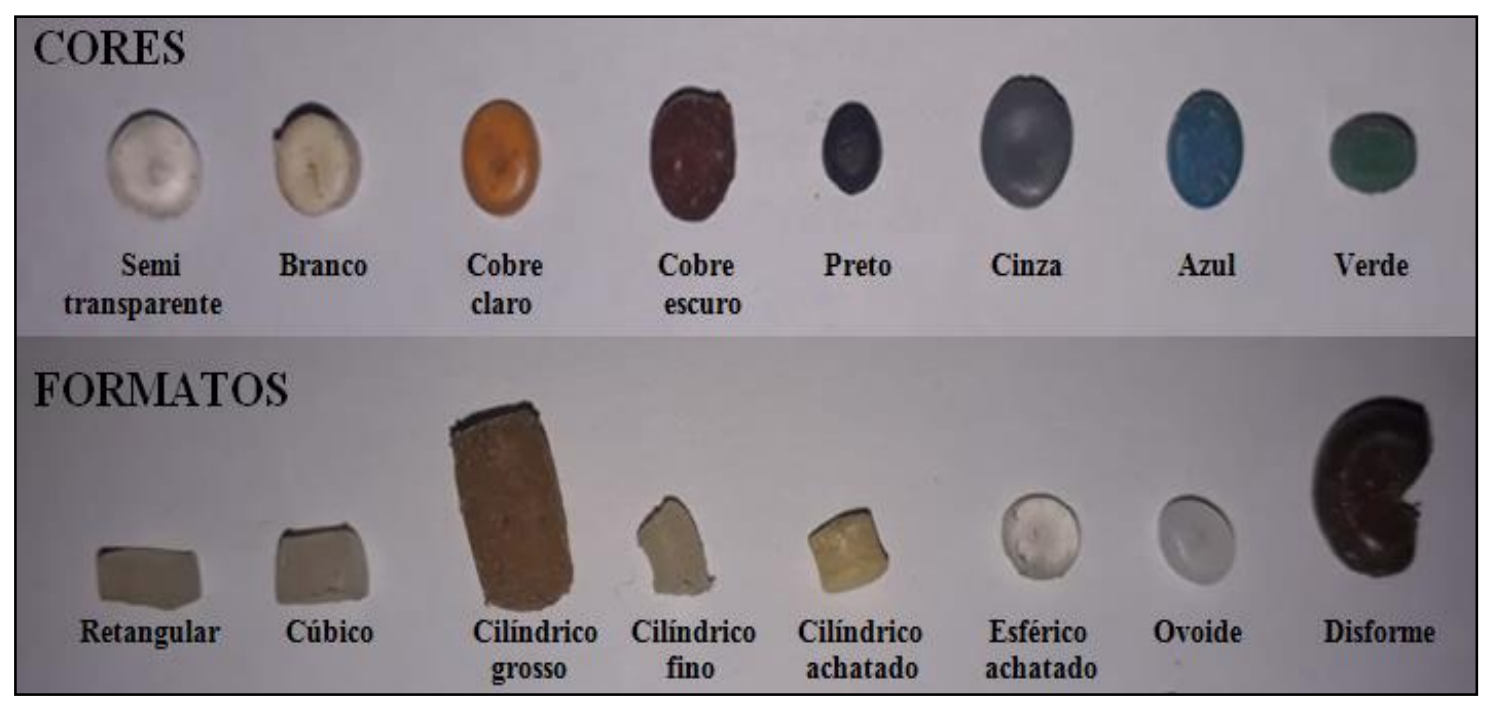

Figura 5. Cores e formatos de pellets Fonte: Arquivo Pessoal, 2019.

De acordo com Hirata (2017), bem como observado no presente estudo, alguns pellets amostrados podem apresentar suas superfícies recobertas por outro material, geralmente de cor preta, que impossibilita a identificação de sua cor original. Todos os grânulos de colorações pretas foram classificados como indefinidos. Tendo em vista que a metodologia adotada não possibilita a suposição do tempo de permanência em ambientes marinhos de pellets de colorações como preto cinza, verde e azul, estes também foram classificados como indefinidos.

Os pellets brancos, semitransparentes e com formato identificável, ou seja, recentemente produzidos, representaram 56,42\% das amostras (Tabela 3). Portanto, as fontes emissoras foram, em sua maioria, classificadas como próximas e que perderam os grânulos ao ambiente marinhos recentemente. Nas praias do Brasil, a maioria dos estudos constatou a presença de pellets de cor branca e transparente, com presenças baixas de outras colorações de grânulos (PIANOWSKI, 1997; BARBIERI, 2009; COSTA et al., 2010; GOUVÊA, 2015; ALVES et al., 2018).

Tabela 3. Classificação morfológica dos pellets

\begin{tabular}{c|cc|cc|cccccc}
\hline Formato & $\begin{array}{c}\text { Semi } \\
\text { trans. }\end{array}$ & Branco & $\begin{array}{c}\text { Cobre } \\
\text { claro }\end{array}$ & Cobre escuro & Preto & Cinza & Azul & Verde & Total & (\%) \\
\hline Retangular & 6 & 1 & 2 & 1 & 0 & 0 & 0 & 0 & 10 & 0,83 \\
Cúbico & 12 & 0 & 3 & 2 & 0 & 0 & 0 & 0 & 17 & 1,42 \\
Cil. grosso & 36 & 11 & 14 & 6 & 15 & 1 & 0 & 0 & 83 & 6,92 \\
Cil. fino & 42 & 6 & 19 & 9 & 13 & 0 & 0 & 0 & 89 & 7,42 \\
Cil. ach. & 197 & 75 & 33 & 26 & 24 & 4 & 1 & 1 & 361 & 30,08 \\
\hline
\end{tabular}


Pellets plásticos na praia de Santa Cruz dos Navegantes, Guarujá (SP), durante evento de frente fria no inverno de 2019

\begin{tabular}{|c|c|c|c|c|c|c|c|c|c|c|}
\hline Esf. ach. & 204 & 79 & 52 & 37 & 19 & 6 & 2 & 1 & 400 & 33,33 \\
\hline Ovoide & 8 & 0 & 1 & 0 & 1 & 0 & 0 & 0 & 10 & 0,83 \\
\hline Disforme & 6 & 31 & 79 & 68 & 46 & 0 & 0 & 0 & 230 & 19,17 \\
\hline \multirow{3}{*}{$\begin{array}{c}\text { Total } \\
\text { (\%) }\end{array}$} & \multicolumn{2}{|c|}{ Recentes" } & \multicolumn{2}{|c|}{ Desgastados $^{* *}$} & \multicolumn{4}{|c|}{ Indefinidos $^{* * *}$} & & \\
\hline & \multicolumn{2}{|c|}{$677^{*}$} & \multicolumn{2}{|c|}{$435^{* *}$} & \multicolumn{4}{|c|}{$88^{* * *}$} & & \\
\hline & \multicolumn{2}{|c|}{$56,42^{*}$} & \multicolumn{2}{|c|}{$36,25^{* *}$} & \multicolumn{4}{|c|}{$7,33^{* * *}$} & & \\
\hline
\end{tabular}

Fonte: Arquivo Pessoal, 2019.

*Brancos e Semitransparentes somados, com exceção dos disformes

${ }^{* *}$ Cobre claros e escuros somados aos disformes de todas as cores

***Preto+cinza+azul+verde, com exceção dos disformes

No verão de 2019, Ribeiro (2019) constatou que os grânulos disformes representavam 24\% das amostras na praia de Santa Cruz dos Navegantes. No presente estudo, no inverno, essa porcentagem foi de 19,17\%. Portanto, as condições meteoceanográficas mais intensas do inverno foram capazes de depositar maior quantidade de pellets recentemente produzidos nesta praia.

Segundo Manzano (2009), nas praias de Santos e São Vicente (SP), a maioria dos grânulos encontrados foi de colorações amareladas, ou seja, desgastados. Portanto, os pellets recentes podem ter como destino de deposição a praia de Santa Cruz dos Navegantes, ao invés das praias de Santos e São Vicente, confirmando novamente o potencial desta praia para pesquisas deste tipo.

\section{CONSIDERAÇÕES FINAIS}

A determinação do período de coleta foi satisfatória, e englobou três campanhas de coleta anteriores e três posteriores ao pico de entrada de frente fria. Os fatores que podem soterrar os pellets foram classificados como baixos, quando comparados a outras praias da região, como São Vicente, e principalmente, Santos. Portanto, a praia de Santa Cruz foi considerada ideal para este tipo de pesquisa na região. Ainda assim, estes fatores podem ter subestimado a quantidade de pellets encontrada.

0 Índice de Poluição por Pellets (IPP) foi de Baixo $(0,679)$ a Muito Alto $(5,105)$, divergindo dos estudos mundiais, que encontraram a maioria de valores Muito Baixos e Baixos. 0 evento de pico de entrada de frente fria influenciou significativamente a quantidade de pellets encontrada, evidenciando novamente a potencialidade desta praia para este tipo de pesquisa. 
A classificação morfológica dos pellets encontrados confirmou a influência do Porto de Santos na deposição desses grânulos e, principalmente na deposição da maioria de grânulos recentemente produzida e perdida aos ambientes aquáticos. A continuidade de estudos que apliquem tais métodos é imprescindível para o monitoramento e a avaliação deste tipo de lixo marinho nesta e em outras regiões.

\section{REFERÊNCIAS BIBLIOGRÁFICAS}

ABIDLI, S.; ANTUNES, J.; FERREIRA, J.; LAHBIB, Y.; SOBRAL, P.; EL MENIF, N.. Microplastics in sediments from the littoral zone of the north Tunisian coast (Mediterranean Sea). Estuarine, Coastal and Shelf Science, v. 205, p. 1-9, 2018.

ALLSOPP, M.; WALTERS, A.; SANTILLO, D.; JOHNSTON, P. Plastic debris in the world's oceans. Amsterdam: Greenpeace International, 2005. $44 \mathrm{p}$.

ALMEIDA, D. M. Presença de microplástico no conteúdo estomacal de peixes de importância econômica em Salvador - BA. 201l. Monografia (Mestrado em Ciências Ambientais) - Universidade Católica do Salvador, Salvador.

ALMEIDA, C. C. Pellets plásticos em praias arenosas em duas áreas portuárias do estado do Ceará. 2018. Dissertação (Mestrado em Ciências Marinhas Tropicais) - Universidade Federal do Ceará, Fortaleza.

ALVES, F. A.; VIANA, E.; UENO, M. H.; SIMÕES, F. A.; FONSECA, H. F. Caracterização de pellets plásticos em praias do litoral norte do estado de São Paulo. Revista Gestão \& Sustentabilidade Ambiental, v. 7, n. 1, p. 300-314, 2018.

ANDRADE, G. F. N. Ocorrência, distribuição e grau de poluição por pellets, lixo de praia e lixo bentônico nas praias do município de Salvador, Bahia, Brasil. 2014. Dissertação (Mestrado em Geologia) - Universidade Federal da Bahia, Salvador.

ANDRADY, A. L. Plastics and their impacts in the marine environment. In: INTERNATIONAL MARINE DEBRIS CONFERENCE, Honolulu, 2000.

ANDRADY, A. L. Microplastics in the marine environment. Marine pollution bulletin, v. 62, n. 8, p. 1596-1605. 2011.

BARBIERI, E. Occurrence of plastics particles in Procellariiforms, South of São Paulo state (Brazil). Brazilian Archives of Biology and Technology, v. 52, n. 2, p. 341-348, 2009.

BLIGHT, L. K.; BURGUER, A. E. Occurrence os plastic particles in seabirds from the Eastern North Pacific. Marine Pollution Bulletin, v. 34, n. 5, p. 323-325, 1997.

B0HM, D. Diálogo: comunicação e redes de convivência. São Paulo: Palas Athena, 2005. 178 p.

BOURNE, W. R. P.; IMBER, M. J.. Plastic pellets collected by a prion on Gough Island, central South Atlantic 0cean. Marine Pollution Bulletin, v. 13, n. 1, p. 20-21, 1982.

BROWNE, M. A.; DISSANAYAKE, A.; GALLOWAY, T. S.; LOWE, D. M.; THOMPSON, R. C. Ingested microscopic plastic translocates to the circulatory system of the mussel, Mytilus edulis (L.). Environmental Science \& Technology, v. 42 , n. 13, p. 5026-5031, 2008.

COLABUONO, F. I., TANIGUSHI, S., MONTONE, R. C. Polychlorinated biphenyls and organochlorine pesticides in plastics ingested by seabirds. Marine Pollution Bulletin, v. 60, n. 4, p. 60-64, 2010. 
Pellets plásticos na praia de Santa Cruz dos Navegantes, Guarujá (SP), durante evento de frente fria no inverno de 2019

COSTA, M. F.; D0 SUl, I. J. A.; SILVA-CAVALCANTI, J. S.; ARAÚJO, M. C. B.; SPENGLER, A.; TOURINHO, P. S. On the importance of size of plastic fragments and pellets on the strandline: a snapshot of a Brazilian beach. Environmental Monitoring and Assessment, v. 168, p. 299-304, 2010.

CUNHA, L. C. Poluição marinha por plásticos: uma questão de direito internacional. Revista do Instituto do Direito Brasileiro, v. 2, n. 12, p. 14473-14500, 2017.

ENDO, S.; MASAKI, Y.; HIDESHIGE, T. Desorption kinetics of hydrophobic organic contaminants from marine plastic pellets. Marine Pollution Bulletin, v. 74, n. 1, p. 125-131, 2013.

EPA. Plastics Pellets in the Aquatic Environment: Sources and recommendations. Environmental Protection Agency. 1992. Disponível em: http://www.globalgarbage.org/13\%20EPA\%20Plastic\%20Pellets.pdf. Acessado em 29 dez 2019.

FALCÃO, P. M.; SOUZA, C. R. G. Avaliação do conhecimento sobre a presença de grânulos plásticos (pellets) em áreas litorâneas do mundo: 1970-2011. In: XIII CONGRESSO DA ASSOCIAÇ̃̃o BRASILEIRA DE ESTUDOS DO QUUATERNÁRIO, São Paulo, 2011.

FALCÃO, P. M. Panorama da poluição costeira por pellets de plástico em praias de SP (Brasil): uma contribuição aos estudos de geografia do litoral. 2015. Tese (Doutorado em Geografia Física) - Universidade de São Paulo, São Paulo.

FANINI, L. Dynamics of plastic resin pellets deposition on a microtidal sandy beach: Informative variables and potential integration into sandy beach studies. Ecological Indicators, v. 89, p. 309-316, 2018.

FERNANDINO, G.; ELLIFF, C. I.; SILVA, I. R. E.; BITTENCOURT, A. C. S. P. How many pellets are too many? The pellet pollution index as a tool to assess beach pollution by plastic resin pellets in Salvador, Bahia, Brazil. Revista de Gestão Costeira Integrada, v. 15, n. 3, p. 325-332, 2015.

FERREIRA, M.L., LOPES, M.A. Análise quali-quantitativa do lixo na praia de Santa Cruz dos Navegantes - GuarujáSp-Brasil. Revista Ceciliana, v. 5, n. 1, p. 30-35, 2013.

FOTOPOULOU, K.; KARAPANAGIOTI, H. K. Surface properties of beached plastic pellets. Marine Environmental Pollution, v. 81, p. 70-77, 2012.

GORMAN, D.; TAVARES M. F.; TURRA, A.; RIBEIR0, F. F.; COMBI, T.; BICEG0, M.; MARTINS, C. (2019). Organic contamination of beached plastic pellets in the South Atlantic: Risk assessments can benefit by considering spatial gradients. Chemosphere, v. 223, p. 608-615, 2019.

G0UVÊA, C. S. C. Caracterização de pellets presentes na praia de Cibratel I, Itanhaém, e sua problemática no ambiente marinho. 2015. Monografia (Graduação em Ciências Biológicas) - Universidade Presbiteriana Mackenzie, São Paulo.

GUIMARÃES, A. R. S. Uso e significado de fitoterápicos em uma comunidade litorânea, município de Guarujá, SP. 2008. Dissertação (Mestado em Saúde Coletiva) - Universidade Católica de Santos, Santos.

HARATSARIS, V. M. PCBs e DDTs em grânulos de plástico depositados em praias do litoral paulista. 2018. Dissertação (Mestrado em Ciências) - Universidade de São Paulo, São Paulo.

HESKETT, M.; TAKADA, H.; YAMASHITA, R.; YUYAMA, M.; ITO, M.; GEOK, Y.B.; OGATA, Y.; KWAN, C.; HECKHAUSEN, A.; TAYLOR, H.; POWELL, T.; MORISHIGE, C.; YOUNG, D.; PATTERSON, H.; ROBERTSON, B.; BAILEY, E.; MERMOZ, J. Measurement of persistent organic pollutants (POPs) in plastic resin pellets from remote islands: Toward establishment of background concentrations for International Pellet Watch. Marine Pollution Bulletin, v. 64, n. 2, p. 445-448, 2012.

HIRATA, G. L. Caracterização e taxa de entrada de pellets plásticos na Praia do Tombo no município de Guarujá - SP. Revista Internacional de Ciências, v. 7, n. 2, p. 202-216, 2017.

IVAR DO SUL, I. J. A.; SPENGLER, A.; COSTA, M. F. Here, there and everywhere. Small plastic fragments and pellets on beaches of Fernando de Noronha (Equatorial Western Atlantic). Marine Pollution Bulletin, v. 58, p. 1229-1244, 2009. 
KARAPANAGIOTI, H. K.; KLONTZA, I. Investigating the properties of plastic resin pellets found in the coastal areas of Lesvos Island. Global Nest Journal, v. 9, n.1, p. 71-76, 2007.

KARAPANAGIOTI, H. K. \& KLONTZA, I. Testing phenanthrene distribution properties of virgin plastic pellets and plastic eroded pellets found on lesvos island beaches (Greece). Marine Environmental Research, v. 65, p. $283-290$. 2008.

KARLSSON, T. M.; ARNEBORG, L.; BROSTRÖM, G.; ALMROTH, B. C.; GIPPERTH, L.; HASSELLÖV, M. The unaccountability case of plastic pellet pollution. Marine Pollution Bulletin, v. 129, p. 52-60, 2018.

LOUR0, P., WIDMER, W. M. Plastic Pellets on Campeche Beach (Santa Catarina Island, Brazil): A Seasonality and Composition Study. Environment and Ecology Research, v. 5, n. 4, p. 302-311, 2017.

MANZAN0, A. B. Distribuição, taxa de entrada, composição química e identificação de fontes de grânulos plásticos na Enseada de Santos, SP, Brasil. 2009. Dissertação (Mestrado em Ciências) - Universidade de São Paulo, São Paulo.

MARINHA DO BRASIL. Tábuas de Maré - Porto de Santos, Torre Grande (Estado de São Paulo). MARINHA, 2019. Disponível https://www.marinha.mil.br/chm/sites/www.marinha.mil.br.chm/files/dados_de_mare/santos_torre_grande_201 9.pdf. Acessado em 21 abr 2019.

MATO, Y.; HERNANDEZ-MILIAN, G.; O'BRIEN, J.; BERROW, S.; O'CONNOR, I.; OFFICER, R. Plastic resin pellets as a transport medium for toxic chemicals in the marine environment. Environmental Science \& Technology, v. 35, n. 2, p. $318-324,2001$.

MIRANDA, D.; CARVALHO-SOUZA, G. Are we eating plastic-ingesting fish?. Marine Pollution Bulletin. v. 1031, n. 2, p. $109-114,2016$.

MÓNICO, L.S.; VALENTIN, R.A.; CASTR0, P.A. A. Observação Participante enquanto metodologia de investigação qualitativa. Investigação Qualitativa em Ciências Sociais, v. 3, p. 724-733, 2017.

MOREIRA, F. T.; PRANTONI, A. L.; MARTINI, B.; ABREU, M. A.; STOIEV, S. B.; TURRA, A. Smallscale temporal and spatial variability in the abundance of plastic pellets on sandy beaches: methodological considerations for estimating the input of microplastics. Marine Pollution Bulletin, v. 102, n. 1, p. 114-121, 2016 a.

MOREIRA, F. T.; BALTHAZAR-SILVA, D.; BARBOSA, L.; TURRA, A. Revealing accumulation zones of plastic pellets in sandy beaches. Environmental Pollution, v. 218, p. 313-321, 2016b.

NOBRE, C. R.; SANTANA, M. F. M.; MALUF, A.; CORTEZ, F. S.; CESAR, A.; PEREIRA, C. D. S.; TURRA, A. Assessment of microplastic toxictity to embryonic development of the sea urchin Lytechinus variegatus (Echinodermata: Echinoideia). Marine Pollution Bulletin, v.92. p. 99-104, 2015.

NPH. NPH-Unisanta informa: Previsão de ressaca a partir desta sexta (2/8) com o pico na madrugada do sábado. NÚCLEO DE PESQUISAS HIDRODINÂMICAS, 2019a. Disponível em: https://noticias.unisanta.br/cienciatecnologia/nph-unisanta-informa-previsao-de-ressaca-a-partir-desta-sexta-2-8-com-0-pico-na-madrugada-dosabado. Acessado em 02 ago. 2019.

NPH. Previsão de mar agitado e maré acima do normal se mantêm até a madrugada de 5/08. NÚCLEO DE PESQUISAS HIDRODINÂMICAS, 2019b. Disponível em: https://noticias.unisanta.br/ciencia-tecnologia/nph-unisantaatualizacao-previsao-de-mar-agitado-e-mare-acima-do-normal-se-mantem-ate-a-madrugada-de-segunda-5-08. Acessado em 03 ago. 2019.

OGATA, Y.; TAKADA, H.; MIZUKAWA, K.; HIRAI, H.; IWASA, S.; ENDO, S.; MATO, Y.; SAHA, M.; OKUDA, K.; NAKASHIMA, A.; MURAKAMI, M.; ZURCHER, N.; BOOYATUMANONDO, R.; ZAKARIA, M. P.; DUNG, L. Q.; GORDON, M.; MIGUEZ, C.; SUZUKI, S.; MOORE, C.; KARAPANAGIOTI, H. K.; WEERTS, S.; McCLURG, T.; BURRES, E.; SMITH, W.; VAN VELKENBURG, M.; LANG, J. S.; LANG, R. C.; LAURSEN, D.; DANNER, B.; STEWARDSON, N.; THOMPSON, R. C. International Pellet Watch: Global monitoring of persistent organic pollutants (POPs) in coastal Waters. 1. Initial phase data on PCBs, DDTs, and HCHs. Marine Pollution Bulletin, v. 58, n. 10, p. 1437-1446, 2009. 
Pellets plásticos na praia de Santa Cruz dos Navegantes, Guarujá (SP), durante evento de frente fria no inverno de 2019

PEREIRA, F. C.; OLIVEIRA, A. L.; TURRA, A.. A Gestão de Resíduos Sólidos no Ambiente Marinho: Pellets Plásticos. In: V Simpósio Brasileiro de 0ceanografia, São Paulo, 2011.

PEREIRA, F. C. Microplásticos no ambiente marinho: mapeamento de fontes e identificação de mecanismos de gestão para minimização da perda de pellets plásticos. 2014. Dissertação (Mestrado em 0ceanografia Biológica) Universidade de São Paulo, São Paulo.

PIANOWSKI, F. Resíduos sólidos e esférulas plásticas nas praias do Rio Grande do Sul - Brasil. 1997. Monografia (Graduação em 0ceanologia) - Universidade do Rio Grande, Rio Grande.

QUEIROZ, H. A. A.; DIAS, S. 0.; GONÇALVES, M. R.; PEREIRA, P. S. Comparação entre dois modelos polinomiais para avaliar a tendência da linha de costa. Revista Brasileira Geomática, v. 4, n. 3, p.160-167, 2016.

RIBEIR0, V. V. Densidade, taxa de entrada e análise morfológica de pellets plásticos na praia de Santa Cruz dos Navegantes, Guarujá - SP. Boletim do Laboratório de Hidrobiologia, v. 29, p. 9-17, 2019.

RYAN, P. G.; PEROLD, V.; OSBERNE, A.; MOLONEY, C. L. Consistent patterns of debris on South African beaches indicate that industrial pellets and other mesoplastic items mostly derive from local sources. Environmental Pollution, v. 238, p. 1008-1016, 2018.

SILVA, C.A.N. A poluição visual causada pelos quiosques na faixa de areia da praia da enseada - Guarujá. Revista Eletrônica de Divulgação Científica, v. 4, 2011.

STEIN, L. P. Morfodinâmica e eventos de sobrelavagem: praias da baía de Santos, SP. 2018. Dissertação (Mestrado em Oceanografia Geológica) - Universidade de São Paulo, São Paulo.

TAKADA, H. Call for pellets! International Pellet Watch Global Monitoring of POPs using beaches plastic resin pellets. Marine Pollution Bulletin, v. 52, n. 12, p. 1547-1548, 2006.

TURRA, A.; MANZANO, A. B.; DIAS, R. J. S.; MAHIQUES, M. M.; BARBOSA, L.; BALTHAZAR SILVA, D.; MOREIRA, F. T. Threedimensional distribution of plastic pellets in sandy beaches: shifting paradigms. Scientific Reports, v. 4, 2014.

VEERASINGAM, S.; MUGILARASAN, R. M.; VENKATACHALAPATHY, P; VETHAMONY, P. Influence of 2015 flood on the distribution and occurrence of microplastic pellets along the Chennai coast, India. Mar. Marine Pollution Bulletin, v. 109, n. 1, p. 196-204, 2016a.

VEERASINGAM S.; MAHUA, V. S.; SUNEEL, P.; VETHAMONY, A. C. R.; SOURAV B.; NAIK, B. G. Characteristics, seasonal distribution and surface degradation features of microplastic pellets along the Goa coast, India. Chemosphere, v. 159, p. 496-505, 2016b. 